\title{
The potential of wire feed pulsation to influence factors that govern weld penetration in GMA welding
}

\author{
Vinicius Lemes Jorge ${ }^{1} \cdot$ Fernando Matos Scotti ${ }^{1} \cdot$ Ruham Pablo Reis $^{1} \cdot$ Américo Scotti $^{1,2,3}$
}

Received: 2 July 2020 / Accepted: 1 September 2020 / Published online: 12 September 2020

(C) The Author(s) 2020

\begin{abstract}
Derivative welding processes are in many cases capable of altering phenomena that determine fundamental aspects of weld bead formation. Some of these evolutions act over the wire feed dynamics. However, in this scenario, the effects of the wire feed pulsation on the weld bead formation governing factors have not been fully explored yet. Therefore, this work aimed at examining how a wire feed pulsation approach affects the droplet transfer in gas metal arc welding and how its interaction with the molten pool defines the weld bead penetration. Bead-on-plate weldments were produced by varying the wire feed pulsation frequency, yet keeping the same levels of arc energy and wire feed speed, with the power source operating in constant voltage and current modes. To assess the droplet transfer behavior, high-speed imaging was used. The geometry of the weld beads was compared in terms of fusion penetration. The results showed that an increase in the wire feed pulsation frequency intensifies the detachment frequency of the droplets, being possible to accomplish a stable metal transfer with them straightly projected toward the weld pool, which contributed to a centralized-increased penetration profile. Based on a descriptive model, it was demonstrated that the increase in droplet momentum or kinetic energy, due to the wire feed pulsation, was not enough to justify the penetration enhancement. It was concluded that the wire feed dynamics can also stimulate surface tension variations in the weld pool and therefore disrupt the behavior of its mass and heat convection, supporting fusion penetration.
\end{abstract}

Keywords GMAW · Wire feed pulsation · Weld bead formation · Penetration · Droplet momentum and kinetic energy · Marangoni flow

Electronic supplementary material The online version of this article (https://doi.org/10.1007/s00170-020-06037-8) contains supplementary material, which is available to authorized users.

Vinicius Lemes Jorge

viniciuslemesj@hotmail.com

Fernando Matos Scotti

fernandomscotti@gmail.com

Ruham Pablo Reis

ruhamreis@ufu.br

Américo Scotti

americo.scotti@hv.se

1 Center for Research and Development of Welding Processes (Laprosolda), Federal University of Uberlandia (UFU), Uberlândia, MG, Brazil

2 Division of Welding Technology, Department of Engineering Science, Production Technology West, University West, Trollhättan, Sweden

3 Graduate Program in Materials Science and Engineering, Federal University of Parana (UFPR), Curitiba, PR, Brazil

\section{Introduction}

In welding, as it happens in other manufacturing fields, the derivative processes (hereafter understood as process versions that were developed from more basic ones) have been under intensive development. They are implemented, in many cases, due to the capability of acting on phenomena that govern important outputs, such as weld bead formation. In gas metal arc welding (GMAW), many of these developments are possible due to technological enhancements in the power sources, generally using fine real-time control of fundamental variables (such as arc voltage and welding current) in order to improve process stability and metal transfer regularity. Some of the most popular and consolidated GMAW derivative processes to control metal transfer are the surface tension transfer (STT), developed by the Lincoln Electric Co. [1], and the regulated metal deposition (RMD), designed by the Miller Electric Mfg. LLC [2].

Besides allowing an efficient control of the power source electric signals, other developments also act over the metal 
feeding dynamics by means of axial pulsation movements of the wire (cyclic advance and retreat motion). An application of such a concept was recently demonstrated by Jorge et al. [3], who introduced a pulsed cold-wire approach to influence the spray GMAW process performance. However, likely the most exploited and prominent technique in this context, and hence discussed hereinafter, was introduced by Fronius International GmbH in 2004, under the Cold Metal Transfer (CMT) brand name. Whereas the material transfer in most of the controlled short-circuit transfer welding processes is solely digitally/ electrically controlled, the CMT version controls the metal transfer with a mechanically assisted digital/electrical method. Later on, the SKS Welding System company launched the microMIG process at the 2009 Essen Welding and Cutting Fair. In this process, the metal transfer is an intercalation of a short-circuiting event and a sequence of free-fall droplets (spray metal transfer). The manufacturer, in this case, claims more control over penetration, yet still with a reduction in spattering and heat input. More details on these processes can be found in Kah et al. [4], but the list of manufacturers that use these concepts is reasonably longer.

Some authors point out that variation in weld bead features can be reached by applying the concept of controlling the dynamics of the wire feeding without any power source output signal control. It is worth making clear that this dynamic feeding consists of a cyclical forward and backward wire motion along the feeding direction itself. To avoid any misunderstanding with the current terminology (mainly concerning the traditional Pulsed GMAW), wire feed pulsation will be always used from now on to indicate such type of wire movement. Wu and Kovacevic [5] showed that the droplet transfer process can be significantly improved by wire feed pulsation, and a projected spray transfer mode can be established at a much lower current level. Also, by increasing the wire feed pulsation frequency, the transfer rate of the droplets was increased while their size decreased. Additionally, these researchers observed an enhancement of the surface quality and a modification of the geometry of the weld beads that could be of importance for overlay cladding and rapid prototyping based on deposition by welding (additive manufacturing). Lebedev et al. [6] verified that the droplet detachment frequency gets close to the set wire pulsation frequency. These authors were able to estimate an optimal point where the mechanical effect imposed by wire feed pulsation prevails over the normal metal transfer, improving stability aspects (less material loss), as well as allowing weld bead geometry control. Guo et al. [7] proposed the employment of wire feed pulsation even for subaquatic flux-cored arc welding (FCAW) aiming at controlling the metal transfer and, thus, enhancing the operation performance. By comparing the results with the conventional wire feeding, the metal transfer and weld bead aspect generated were improved when the wire pulsation was applied, especially for frequencies between 30 and $40 \mathrm{~Hz}$. In addition, while further researching the topic, Guo et al. [8] verified that, for a same wire feed pulsation mode and frequency, the weld bead formation and process stability were better when the backward wire motion speed was slower and the retreat distance was shorter. Nevertheless, although there are results indicating that the wire feed pulsation might affect the weld bead formation, its relationship with the factors that govern the related phenomena has not been explored yet.

The complexity involved to properly study the governing factors in the weld bead formation is remarkable. According to Scotti and Ponomarev [9], the weld bead formation is ruled by two effects, namely, the thermal effect and the mechanical effect, as scrutinized in Fig. 1. According to this figure, the mechanical effect depends on three mechanisms: the impact of the droplets impinging the liquid metal $(\mathrm{C})$; the pressure of the plasma jet itself inflicting on the liquid metal (D); and the pressure of the magnetic field induced by the welding current flow (E). Note that a buoyancy force, a stirring force, and a linear momentum could be assigned as the mechanism (C). Thereby, it can be presumed that, when applying wire feed pulsation in the GMAW process, there is an implied modification in the droplet dynamics (size, shape, transfer rate, and speed) as well as in the arc behavior. This modification, in turn, directly affects the mechanical effect and unfolds, through the droplet transfer, the thermal effect. These intricate and crossed relationships make the proper understanding of the weld bead formation quite a challenge. Back to the mechanical effect, the mechanisms (D) and (E) could suffer variations due to the wire feed pulsation, since the arc and weld pool coupling area, even the welding current, would change according to the wire back and forth motion. For example, when the GMAW power source is in constant voltage mode, the current increases when the wire approaches the weld pool and decreases when it retreats. However, the focus of this study will be mainly on the mechanism (C), which acts directly over the droplet dynamics and could significantly affect the process performance.

Concurrently or not, another mechanism capable of acting on the weld bead formation, yet not mentioned in Fig. 1, is referenced in the literature as the Marangoni flow, a phenomenon named after the Italian physicist Carlo Marangoni, who originally studied the mass transfer along an interface between two fluids due to a gradient of surface tension. According to Dass and Moridi [10], the Marangoni flow happens due to a convective heat transfer phenomenon within the molten pool. Heiple et al. [11], in 1982, postulated that Marangoni forces generated due to the differences in surface tension and temperatures in the molten pool boost the circulation of its mass. According to their theory, this movement occurs mainly from regions of low to high surface tensions, ultimately leading to changes in the molten pool, and hence in the weld penetration. According to Mills [12], since there is a large temperature 


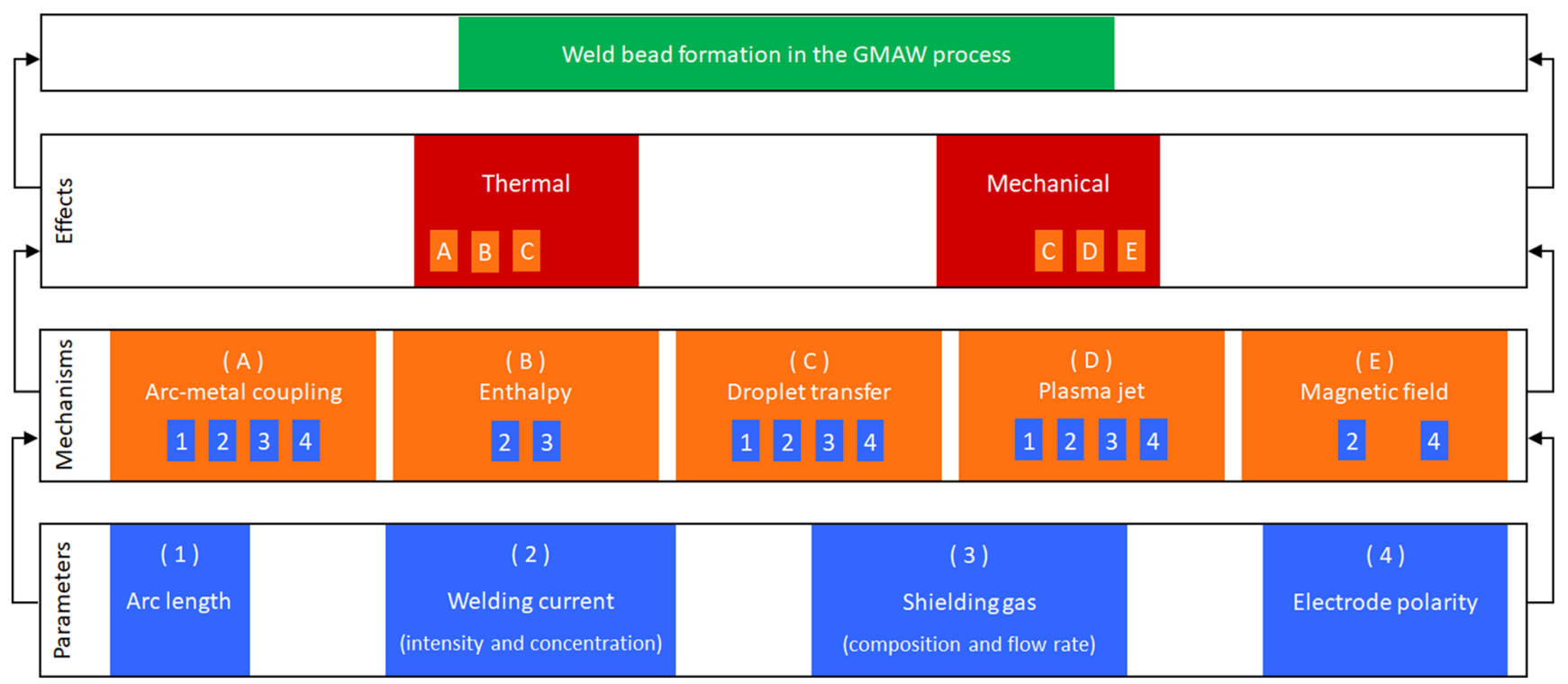

Fig. 1 Hierarchical representation of the weld bead formation phenomena in the GMAW process (adapted from Scotti and Ponomarev [9])

gradient between the center and the edges of the weld pool, a surface tension gradient is entailed and causes fluid circulation (from low to high surface tension regions). However, the nature of the surface tension gradient will determine the flow circulation pattern. Usually, for pure metals and low oxygen and sulfur contents, the surface tension has an inverse correlation with the temperature, resulting in a flow from the center towards the edges. The addition of oxygen and sulfur as alloy elements is capable of altering the relationship between temperature and surface tension; i.e., they become directly proportional. Thus, an inward flow can be established in the weld pool. In autogenous gas tungsten arc welding (GTAW) assisted by solid active fluxes applied onto the base metal surface, this mechanism is widely discussed by some authors [13-15] in order to justify deeper and narrower weld beads obtained with the same arc energy. These fluxes contain chemical elements that are capable of changing the weld pool surface tension behavior and therefore its mass and heat convection patterns. This GTAW process variation is usually referred to as active flux TIG (A-TIG).

It is worth citing that, for a process with the addition of metal, Choo et al. [16] drew attention to the fact that the droplets under transference also induces Marangoni flow in the weld pool. To demonstrate it, they proposed a physical model to simulate the interaction between the droplet and the weld pool in the GMAW process. Based on the fact that the droplets may have different surface tension and density in relation to the pool, they demonstrated that the surface tension force generated the strongest flow when compared with the buoyancy and stirring forces induced by the same falling droplets. According to them, this droplet-induced Marangoni flow can also control the direction and the intensity of the fluid flow. If the droplet has a larger surface tension than the pool, then the surface flow is directed inward and a deep flow loop is created (and the other way around). Therefore, they suggest that the role played by the Marangoni flow induced by the droplets should not be set aside when analyzing the molten metal flow in the GMAW process. They also conclude that the momentum of a falling droplet was not sufficient to cause it to penetrate the pool. However, it is important to mention that they have not assessed a possible influence of multiple droplets sequentially impinging the weld pool.

To some extent in accordance with Choo et al.'s [16] findings, Davies et al. [17] showed that the metal transfer in GMAW has great influence in the convective flow behavior in the weld pool. By modifying the sulfur content in the droplets, they proposed a computational model to assess the influence of surface tension differences between the droplet and the pool over the convective flow. They concluded that the flow induced by the relative surface tension between the droplets and the pool can only influence weldments made with currents below 150 A. For currents around $200 \mathrm{~A}$, the increase in the droplet momentum becomes prominent and superimposes the surface tension effect. The model proposed by Jaidi and Dutta [18] also shows that the flow and the dynamic behavior of the weld pool in GMAW have great influence over the final weld bead geometry and heat-affected zone (HAZ). Still regarding the material flow behavior in welding, Jaidi and Dutta [19], through a tridimensional model, studied the interaction between the forces that can generate turbulence in the weld pool, which changes its convection profile and possibly alters the bead geometry and HAZ. They discuss that the effect of the droplet fall and the thermal diffusivity in GMAW intensified as a result of the turbulence, would tend to make the molten pool deeper, i.e., increase weld penetration. Differing from Davies et al. [17], Jaidi and Dutta [19] found evidence that the Marangoni flow phenomenon has an important role in weld bead formation, even for currents above $150 \mathrm{~A}$. 
As seen, the idea of pulsing the wire feeding has been partially explored as an attempt to improve the GMAW process, but there have been limited studies dealing with the phenomena involved behind this derivative approach, which is key for its proper industrial success and the full exploitation of its potentialities. As important as proposing different mechanisms to perform the wire feed pulsation, it is fundamentally imperative to seek the understanding of how the dynamics of the pulsed wire interferes in the weld bead formation, i.e., in its governing factors. Therefore, this work aims at contributing to this scenario by examining how a wire feed pulsation approach affects the transfer of the metal droplets and their interaction with the molten pool to define the weld bead geometry in terms of penetration in the GMAW process.

\section{Methodology and experimental procedure}

The methodological approach applied in this work was based on bead-on-plate weldments. As variables, a range of wire feed pulsation frequencies and two power source setups were employed. An electronic power source for the GMAW process was set to either constant voltage (CV) or constant current (CC) operational modes, keeping a same level of arc energy. The welding parameters always targeted a globular transfer mode. When pulsing the wire feeding, the amplitude of its forward and backward movement was kept always constant. To allow the assessment of the metal transfer behavior toward the weld pool, high-speed imaging was used. The resulting weld bead geometries were compared among the samples in terms of fusion penetration.

The wire feed pulsation was accomplished by means of an original home-developed device that superimposes a pulsation movement to the wire, in a forward-backward position cycle, over its continuous movement provided by the wire feeder. A comprehensive description of such a device has been revealed by Reis et al. [20] and Jorge et al. [21]. Figure 2 illustratively summarizes it along with a schematic position-versus-time diagram for both its actuator and the wire tip at the welding zone (the wire feed speed is not taken into account). By working independently, this device can be coupled with and/or in between any conventional feeder and torch and allows the configuration of the acceleration, deceleration, and speed of the advance and retreat movements of the wire, as well as of the dwell time at its retreated position, enabling the achievement of customized wire feed pulsation waveforms. In the current work, the settings of such a device were selected for the highest possible acceleration/deceleration and speed during the advance and retreat movements of the wire, targeting a maximum contribution in terms of the mechanical impulse to the droplet detachment from its tip. The pulsation frequency was selected by setting the dwell time at the wire backward position, being the dwell time in the forward position always nil.

The bead-on-plate GMAW weldments were carried out onto ASTM 1020 test plates of $160 \times 32 \times 6.4 \mathrm{~mm}$. The main settings were wire feed speed $(\mathrm{WFS})=4.8 \mathrm{~m} / \mathrm{min}$, wire feed pulsation amplitude $=4 \mathrm{~mm}$, welding travel speed $(\mathrm{TS})=$ $20 \mathrm{~cm} / \mathrm{min}$, and contact-tip to work distance $(\mathrm{CTWD})=$ $19 \mathrm{~mm}$. An AWS ER70S-6 wire (1.0 $\mathrm{mm}$ in diameter) and a blend of argon with $25 \% \mathrm{CO}_{2}$ (flow rate of $16 \mathrm{~L} / \mathrm{min}$ ) as shielding gas were employed. Data acquisition (electric voltage and current) was carried out by an A/D board at a rate of $5 \mathrm{kHz}$ and with 14 bits of resolution (for $40 \mathrm{~s}$ during each run). Each run was filmed using a high-speed camera operating at $2000 \mathrm{frames} / \mathrm{s}$, with a shutter speed of 1/200000 s and synchronized with the data acquisition. A He-Ne laser (wavelength of $632.8 \mathrm{~nm}$ ) was used for back-lighting, and a narrow bandpass optical filter (wavelength range of $632.8 \pm 5 \mathrm{~nm}$ ) was utilized to block almost the full arc light. For geometrical analysis purposes, three cross-sections were cut off from each weld bead. After proper polishing and etching (Nital 8\%), the weld penetration was measured by using a digital image analysis software.

A one-step-at-a-time experimental procedure was executed according to the design displayed in Table 1 . When the wire feed pulsation was activated, the same basic motion waveform illustrated in Fig. 2 was maintained for all the runs. However, the wire feed pulsation frequency was progressively increased from run 1 to 4 , keeping the other parameters unaltered and with the power source in the $\mathrm{CV}$ mode. Two additional runs (5 and 6), analogous to runs 2 and 3, were executed in order to examine the use of the power source in the $\mathrm{CC}$ in opposition to $\mathrm{CV}$ mode and to assess the possible changes in the process behavior with the pulsed wire feeding. For both power source operational modes, the arc energy was kept the same. The low current intensities and the small deviation between their mean and RMS values indicate that the pursuit of a globular metal transfer succeeded.

\section{Results and preliminary discussion}

\subsection{Effect of wire feed pulsation on the metal transfer}

To explore the effect of the wire feed pulsation on the metal transfer, the time intervals between each droplet detachment were registered, sampling thirty consecutive events from the high-speed imaging. The mean value of these intervals $\left(T_{d}\right)$ represents the droplet detachment period, and consequently, its inverse represents the droplet detachment frequency $\left(f_{d}=1 / T_{d}\right)$. Figure 3(a) shows the results of the droplet detachment period for each condition tested. It must be highlighted that the standard deviation, in this case, might be considered a regularity index 

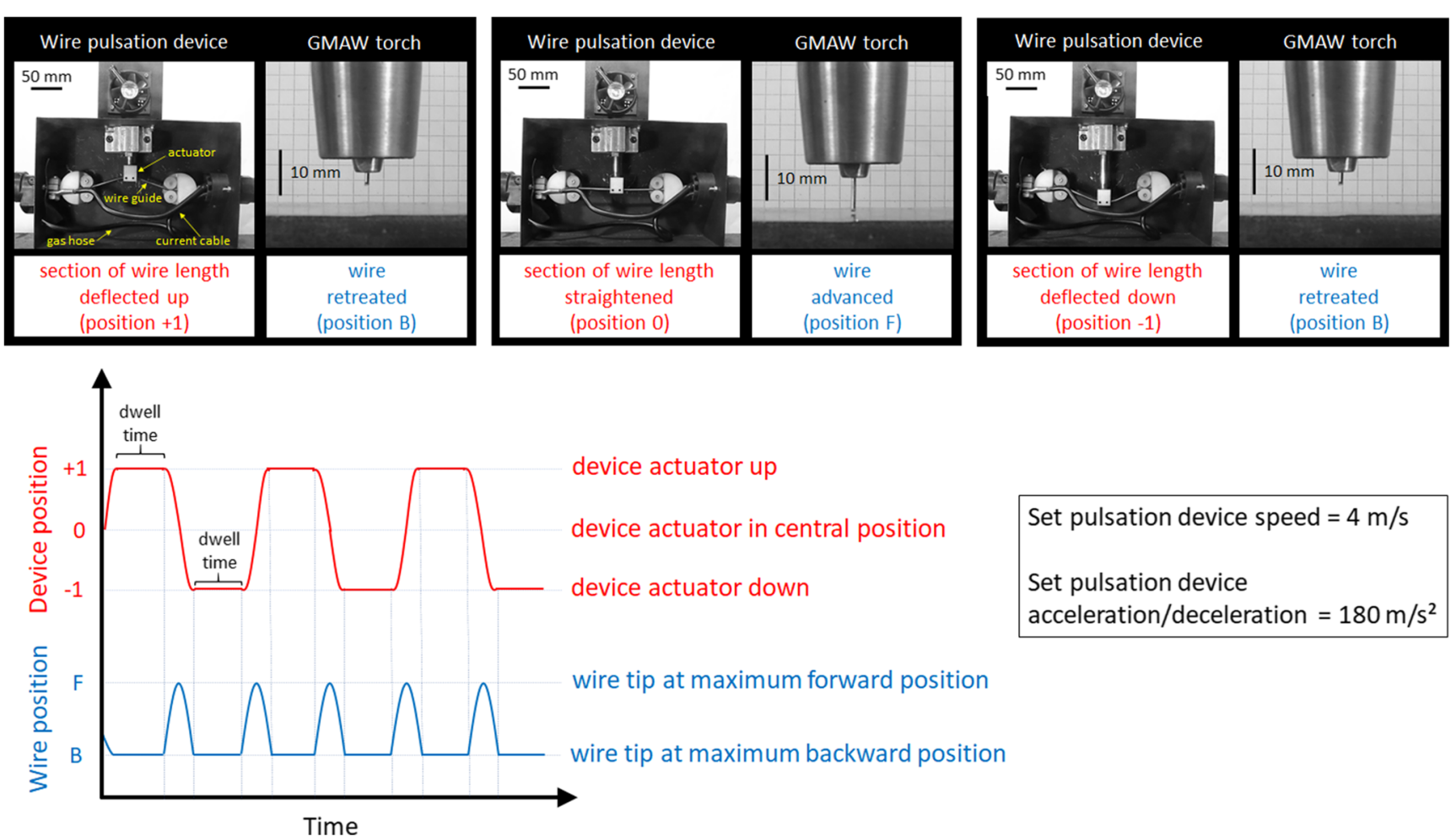

Fig. 2 Illustration of the wire feed pulsation stages along with a schematic temporal position diagram for both the device actuator and the wire tip at the welding zone (the wire feed speed is not taken into account)

concerning the droplet formation and detachment. A high standard deviation in the detachment period indicates a large variability in the time available for the droplets to grow, which leads to wide variability in the volume of the detached droplets. Following this criterion, the experiment without wire feed pulsation is characterized by large droplet sizes (globular transfer) and high variability in the volume of the detached droplets, which is typical of a metal transfer without any control. In contrast, a higher detachment regularity was noticed when the pulsation frequencies of 8 and $16 \mathrm{~Hz}$ were applied with the power source in the CV mode. Figure 3(b), in turn, shows that, for these cases, the pulsation frequency matches the detachment frequency, meaning that a droplet is detached from the tip of the wire for each mechanical cycle applied to it. More specifically, the droplet is observed to be detached at the end of the advance movement. For the $26 \mathrm{~Hz}$ frequency, the regularity decreases and the pulsation frequency does not match the detachment frequency anymore (Fig. 3(b)). In other words, for this condition, some droplets are not detached at the end of the wire advance movement. The sequence of frames sampled from this case and shown in Fig. 4 presents a situation when a droplet does not detach from the tip of the wire, despite

Table 1 Experimental design and electrical parameters monitored/calculated

\begin{tabular}{|c|c|c|c|c|c|c|c|c|}
\hline Run & $\begin{array}{l}\text { Wire pulsation } \\
\text { frequency } \\
(\mathrm{Hz})\end{array}$ & $\begin{array}{l}\text { Power source } \\
\text { mode }\end{array}$ & $\begin{array}{l}\text { Set voltage } \\
\text { (V) }\end{array}$ & $\begin{array}{l}\text { Set current } \\
\text { (A) }\end{array}$ & $\begin{array}{l}\text { Monitored } \\
U_{\text {mean }} \\
\text { (V) }\end{array}$ & $\begin{array}{l}\text { Monitored } \\
I_{\text {mean }} \\
\text { (A) }\end{array}$ & $\begin{array}{l}\text { Monitored } \\
I_{\mathrm{rms}} \\
(\mathrm{A})\end{array}$ & $\begin{array}{l}\text { True arc } \\
\text { energy } \\
(\mathrm{kJ} / \mathrm{mm})\end{array}$ \\
\hline 1 & 0 & $\mathrm{CV}$ & 31.5 & - & 33.7 & 153.4 & 154.6 & 1.55 \\
\hline 2 & 8 & & & & 33.9 & 148.9 & 153.8 & 1.51 \\
\hline 3 & 16 & & & & 33.7 & 149.0 & 151.7 & 1.50 \\
\hline 4 & 26 & & & & 33.9 & 149.0 & 150.5 & 1.53 \\
\hline 5 & 8 & $\mathrm{CC}$ & - & 155 & 35.2 & 154.2 & 154.3 & 1.62 \\
\hline 6 & 16 & & & & 35.3 & 154.2 & 154.2 & 1.63 \\
\hline
\end{tabular}

$U_{\text {mean }}=$ mean arc voltage; $I_{\text {mean }}=$ mean welding current; $I_{\text {rms }}=$ root mean square welding current; True arc energy as calculated by the average of the instantaneous electrical power divided by the travel speed; wire pulsation frequency $=0$ means a condition with no wire feed pulsation; WFS $=4.8 \mathrm{~m} /$ min; wire feed pulsation amplitude $=4 \mathrm{~mm} ; \mathrm{TS}=20 \mathrm{~cm} / \mathrm{min} ; \mathrm{CTWD}=19 \mathrm{~mm}$ 

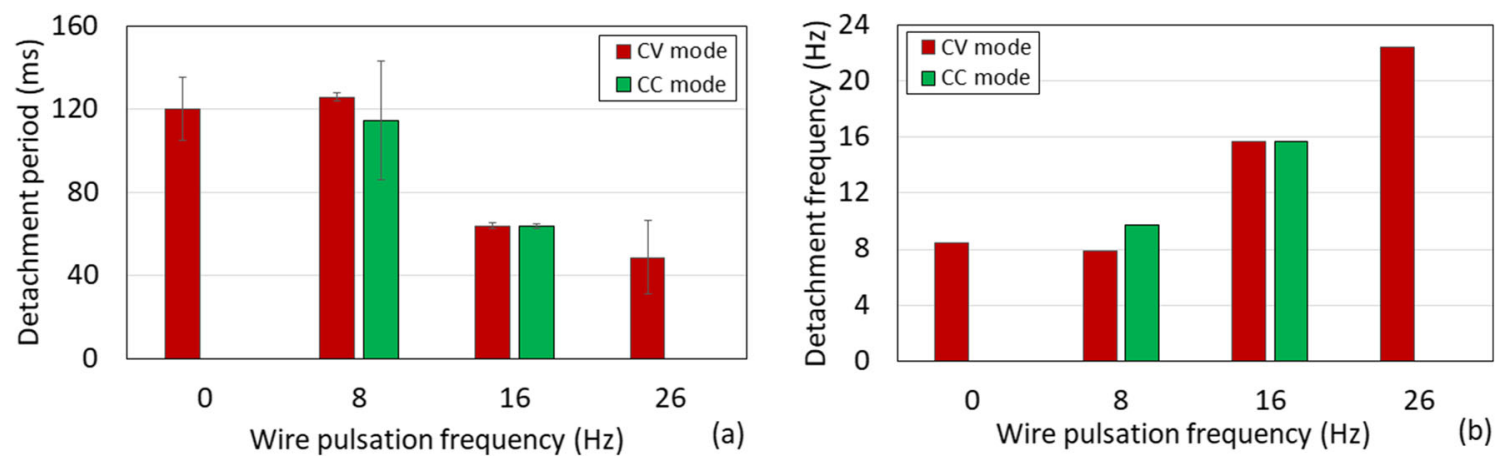

Fig. 3 Dynamics of the metal transfer according to the power source operational mode as a function of the wire feed pulsation frequency: (a) Droplet detachment period; (b) Droplet detachment frequency

the mechanical action imposed by the pulsation device. Since the dwell time (see Fig. 2) at $26 \mathrm{~Hz}$ is shortened, on several occasions, the droplets do not grow enough to be detached in this condition, even with the mechanical impulse provided.

Still from Fig. 3(a), the detachment regularity for the pulsation frequency of $8 \mathrm{~Hz}$ when the power source was in the $\mathrm{CC}$ mode is lower when compared with the same frequency applied with the $\mathrm{CV}$ mode. The next sequence of sampled frames, shown in Fig. 5, illustrates a phenomenon observed during the metal transfer for this condition, i.e., the droplets were naturally released once a critical size was reached, with the wire feed pulsation advance movement coming too late to affect it (premature detachments). In CV mode, the welding current increases when the wire is moving forward and decreases when it is moving backward. In contrast, the current is kept at a steady level when using the power source in CC mode. This constant current makes the droplet growth process somewhat uncontrollable, and the detachment occurrence does not match the wire advance movement action. However, with the pulsation frequency at $16 \mathrm{~Hz}$, the wire feed movement action takes place quickly enough to avoid premature detachments. In fact, at $16 \mathrm{~Hz}$, sound detachment regularities were achieved with both the $\mathrm{CC}$ and $\mathrm{CV}$ modes. At this frequency, the mechanical action of the wire feed pulsation device assisted to produce forced detachment of smaller droplets with both operational modes.
In order to quantify the mean droplet volumes, video frames from eight random droplets on the verge of detachment were selected for each parameter combination (experimental runs). By assuming that the droplet shape just before detachment is described by an oblate ellipsoid of revolution (radius $a=b<c$ ), the respective volumes were estimated through Eq. 1. The major (a) and minor (c) ellipsoid radius were measured utilizing an image analysis software. The product of each droplet volume $\left(V_{d}\right)$ and the liquid metal density $(\rho)$ gives the mass of each droplet $\left(m_{d}=\rho . V_{d}\right)$. The density value was adopted as being $7040 \mathrm{~kg} / \mathrm{m}^{3}$, by considering common steel in the liquid state [22].

$V_{d}=\frac{4 \pi}{3} \cdot a^{2} c$

Figure 6 presents the mean values of both the volume and mass of the droplets for each condition. As seen, as the wire feed pulsation frequency increases, the droplet size (volume and mass) decreases. This clear trend confirms that the impulse action provided by the wire feed pulsation device induces the detachment of smaller droplets. Although the statistical significance is not high (relatively large standard deviations), one could suggest that the droplet is smaller for the $8 \mathrm{~Hz}-\mathrm{CC}$ condition when compared with the $8 \mathrm{~Hz}-\mathrm{CV}$ one. In $\mathrm{CC}$ mode, since the droplets detach independently from the imposed mechanical action, the detachment frequency is
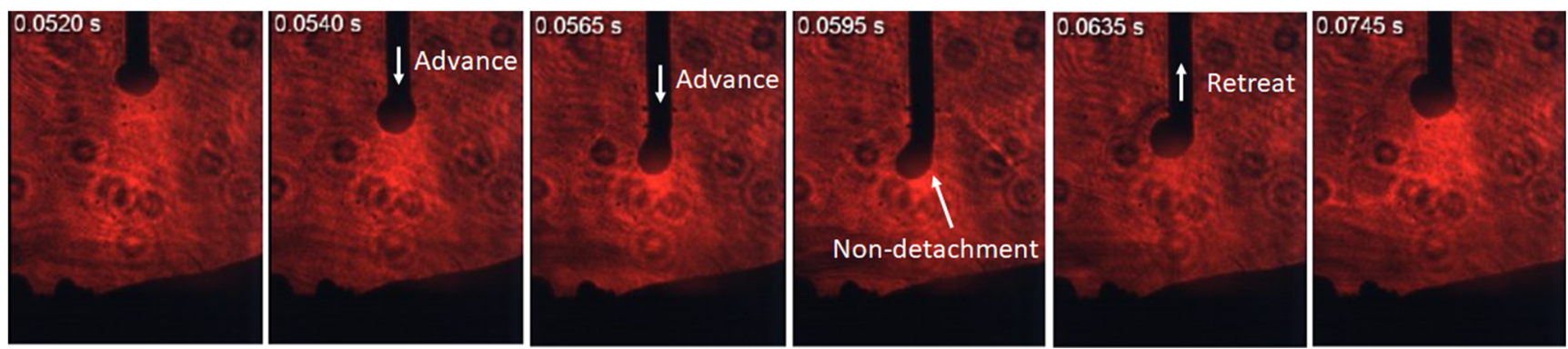

Fig. 4 Non-detachment of droplet observed during a cycle of movement with the wire feed pulsation frequency at $26 \mathrm{~Hz}$ and the power source in $\mathrm{CV}$ mode $(26 \mathrm{~Hz}-\mathrm{CV})$ 

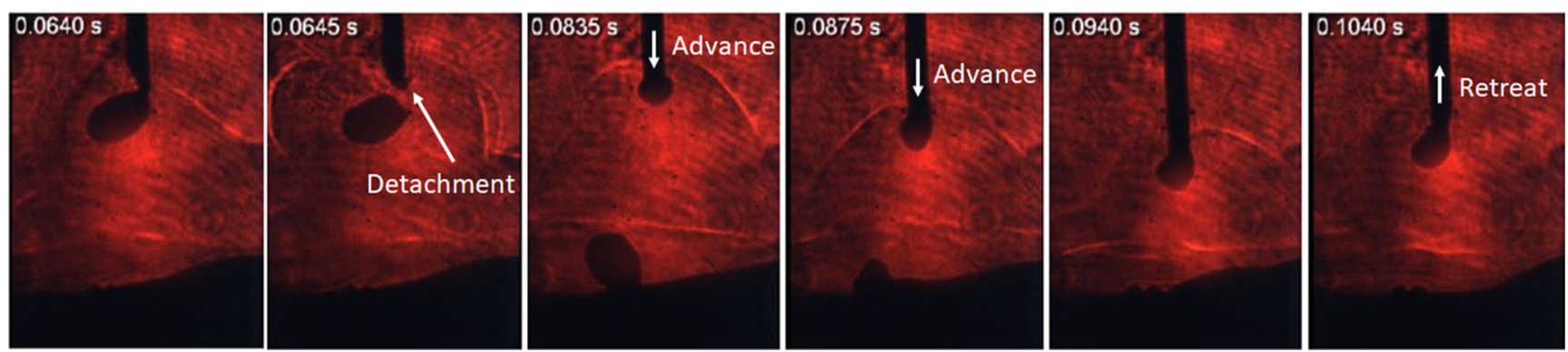

Fig. 5 Occurrence of droplet premature detachment observed during a cycle of pulsing movement with the wire feed pulsation frequency at 8 Hz and the power source in $\mathrm{CC}$ mode $(8 \mathrm{~Hz}-\mathrm{CC})$

higher than the pulsation frequency, i.e., more droplets of smaller sizes are transferred (reminding that the WFS value, consequently the melting rate, was the same for all the runs). Nonetheless, the same reasoning cannot be applied when comparing the volume/mass of the droplets at $16 \mathrm{~Hz}$ of wire feed pulsation with both operational modes, since the average value differences are smaller and the standard deviations are still relatively high.

Preliminarily, the average speed of the droplets in each condition was estimated by measuring the distance traveled by them between the position where their detachment happened and the position just before they touched the molten pool divided by the elapsed time, always for eight consecutive droplets. Further up, to estimate the arrival speed achieved by the droplets, i.e., just before their diving moment into the weld pool, respective positionversus-time curves were built by using ten to sixteen frames (depending on the number of images available according to each droplet speed) sampled from the highspeed footages. From the curves, a polynomial fit was assembled, from which the derivative function represents the speed over time. The arrival speed of each case was then calculated for the last time value before the droplet reached the weld pool. Since this procedure was laborious and time-consuming, only one droplet for each condition was analyzed. However, by comparing the trends of arrival and average speeds, as shown in Fig. 7, the similarity

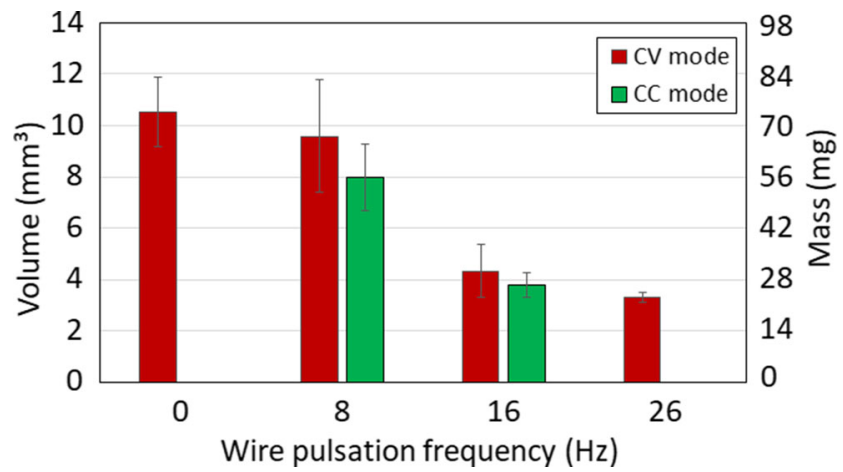

Fig. 6 Mean values of volume and mass of the droplets on the verge of detachment as a function of the wire feed pulsation frequency for both power source operational modes indicates good representability of the arrival speed values. The order of magnitude of the droplet arrival speed in Fig. 7 for the condition without wire feed pulsation $(0.53 \mathrm{~m} / \mathrm{s}$ for a setting of $153 \mathrm{~A}$ and $33.7 \mathrm{~V}$ ) is in fair agreement with the values found by Scotti and Rodrigues [23], who used a more robust measurement method. In their work, in similar conditions (ER70S-6 $\varnothing 1.2 \mathrm{~mm}$ and $\mathrm{Ar}+5 \% \mathrm{O}_{2}$ ), the droplet arrival speed was around $0.53 \mathrm{~m} / \mathrm{s}$ for a set of $200 \mathrm{~A}$ and $29.8 \mathrm{~V}$ and $0.66 \mathrm{~m} / \mathrm{s}$ for a set of $200 \mathrm{~A}$ and $34.9 \mathrm{~V}$.

In addition, Fig. 7 shows that the mechanical impulse action, created by the application of the wire feed pulsation, was capable of increasing the droplet arrival speed. One can assume that the arrival speed of the droplets would be the same for all the wire pulsation frequencies evaluated since the applied mechanical impulse was also the same. However, for the $8 \mathrm{~Hz}-\mathrm{CC}$ condition, its value was lower. As previously discussed, in this case, the droplets detach before the impulse action; i.e., their detachment frequency does not coincide with the wire feed pulsation frequency. Therefore, the mechanical

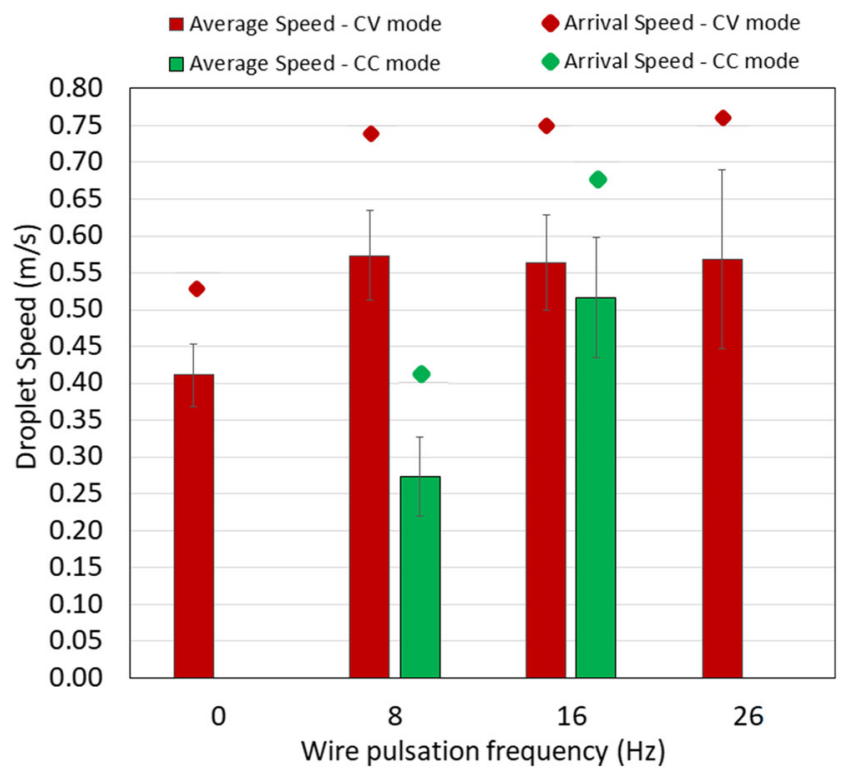

Fig. 7 Average speed of the droplets and arrival speed of the droplets on the verge of diving into the weld pool as a function of the wire feed pulsation frequency for both power source operational modes 
impulse does not project the droplets as in the other conditions, not being then able to increase their arrival speed at the weld pool. By observing the increase and inter-similarity in the arrival speed of the droplets in the $16 \mathrm{~Hz}-\mathrm{CC}$ and $16 \mathrm{~Hz}$ $\mathrm{CV}$ conditions, for this wire pulsation frequency, it can be said that the mechanical impulse tends to overcome any effect that depends on the power source operational mode.

\subsection{Effect of wire feed pulsation on the weld bead penetration}

Figure 8 presents the typical weld bead cross sections sampled for each welding condition evaluated. Figure 9 shows the mean values compiled for the weld bead penetration linearly measured at the deepest bead point and based on three crosssections for each case. It is possible to notice an expressive trend of growth in the weld penetration as the wire feed pulsation frequency increases for both operational modes $(\mathrm{CV}$ and $\mathrm{CC}$ ) of the power source. However, this increase in penetration was more pronounced with the $\mathrm{CV}$ mode; the wire feed pulsation was capable of increasing the penetration around $75 \%$ when the $16 \mathrm{~Hz}-\mathrm{CV}$ condition was applied in comparison with the $0 \mathrm{~Hz}-\mathrm{CV}$ one. With the wire feed pulsation frequency specifically at $16 \mathrm{~Hz}$, the weld beads revealed a fusion profile more concentrated in the center region (commonly known in welding as finger-like penetration). Concerning the whole penetration area (molten material below the plate top surface), it can be visually noticed that it

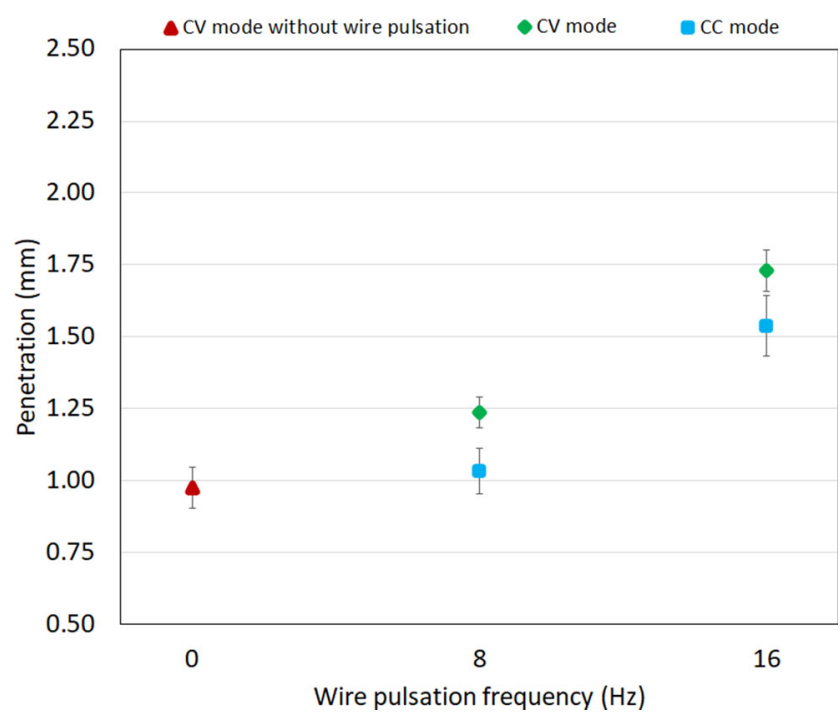

Fig. 9 Mean values of weld bead penetration as a function of the wire feed pulsation frequency for both power source operational modes

followed the same tendency. Therefore, the mechanical impulse, provided by the wire feed pulsation device as applied, is capable of increasing the weld bead penetration in the GMAW process with a globular metal transfer. This effect seems to be justifiable by a droplet-throwing action that the wire feed pulsation technique imposes with the conditions employed (the pulsation settings were selected to deliver the highest possible acceleration/deceleration and speed during the advance and retreat movements of the wire).
Fig. 8 Typical weld bead cross sections sampled for each wire feed pulsation frequency and power source operational mode combination (at $26 \mathrm{~Hz}$, despite the proper arc stability, there was no enough welding time to deposit long weld beads that would allow reliable penetration measurements due the proximity to the existing set limit of pulsation frequency)
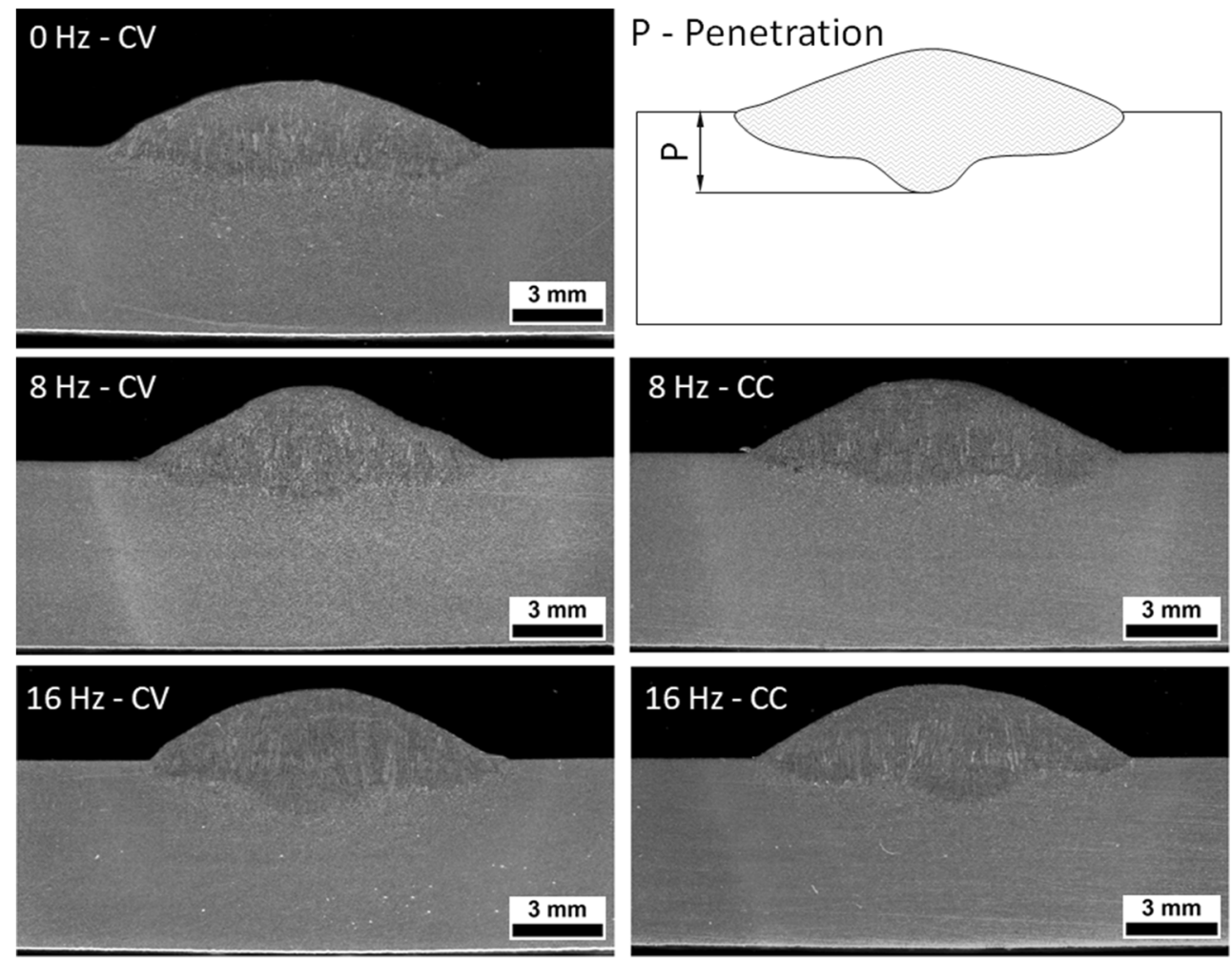


\section{Main discussion}

\subsection{Effect of wire feed pulsation on the metal transfer}

The results presented in section 3.1 suggested that the action of the mechanical impulse applied by the pulsation device to the electrode-wire was able to assist the detachment of the droplets, increasing their speed on the verge of diving into the weld pool, turning the droplets less voluminous and making the detachment more frequent in the same pace as the wire feed pulsation increases. The metallic transfer in the GMAW process is a complex phenomenon since it is influenced by several factors, such as material, electrode diameter, shielding gas, intensity, and polarity of the welding current, arc length, among others. The droplets remain all the time subjected to the action of a series of forces that may or may not act favorably to their detachment. A droplet is transferred when the sum of the detachment forces exceeds the sum of the retention forces (model known as static force balance, acceptable for globular transfer).

For a conventional (without wire feed pulsation) globular metal transfer and considering a flat-position welding situation, Fig. 10 represents a model of natural detachment. The main forces acting on a droplet during its growth and before its detachment are the gravitational force $\left(F_{g}\right.$-in favor of the detachment due to the Earth's gravitational field) and the surface tension force ( $F_{y}$ - against the detachment due to the molten metal surface tension). The $F_{\gamma}$ and $F_{g}$ values are respectively calculated according to Eqs. 2 and 3 . The speed $s_{i}$ corresponds to the initial speed achieved by the droplet before its detachment (assumedly the same as the wire feed speed), and $s_{a}$ corresponds to its speed at the arrival on the weld pool. As seen, to calculate $F_{v}$, it is necessary to estimate the droplet diameter $\left(d_{d}\right)$ and the surface tension coefficient $(\gamma)$. The $F_{g}$ value obviously depends on the droplet mass $\left(m_{d}\right)$ and the gravitational acceleration $(g)$. Based on this simplified model of natural detachment, in the eminence of the droplet detachment (situation 2 of Fig. 10), there is a transitory equilibrium of the $F_{r}$ and $F_{g}$ magnitudes. In this manner, it is possible to estimate $\gamma$ through Eq. 4, from the measurements of the diameter and mass of the droplets carried out earlier in this work for each sample of droplets.

Fig. 10 Simplified physical model of a droplet detachment under the conventional (without wire feed pulsation) globular metal transfer, where $m_{i}$ is the droplet initial mass in $\mathrm{kg} ; m_{d}$ is the droplet mass in $\mathrm{kg} ; F_{g}$ is the gravitational force in $\mathrm{N} ; F_{\gamma}$ is the surface tension force in $\mathrm{N}$; and $s_{i}$ and $s_{a}$ are, respectively, the initial and arrival droplet speed in $\mathrm{m} / \mathrm{s}$
$F_{\gamma}=\pi \cdot d_{d} \cdot \gamma[\mathrm{N}]$

$F_{g}=m_{g} \cdot g[\mathrm{~N}]$

$\gamma=\frac{m_{d} \cdot g}{\pi \cdot d_{d}}[\mathrm{~N} / \mathrm{m}]$

Figure 11 represents a model of a droplet detachment under globular metal transfer assisted with the wire feed pulsation. When the pulsation is applied to the wire, the acceleration imposed on its advance movement, and in turn to the droplet still attached to its tip, creates an extra force that does not exist in the above-mentioned static force equilibrium equation. This impulse force $\left(F_{i}\right)$, due to the mechanical impulse, adds to the $F_{g}$ value to overcome the $F_{Y}$ magnitude, and therefore, to detach the droplets. The $F_{i}$ value can be estimated through Eq. 5, as a direct deduction from the momentum variation and impulse equations from the classical mechanics (the mechanical impulse applied to an object produces an equivalent vector change in its linear momentum). The parameter $s_{d}$ corresponds to the maximum speed achieved by the droplet before its detachment and the $\Delta t_{a}$ corresponds to the respective elapsed period during the advance movement of the wire. Since all conditions operated with the same mechanical impulse (see Fig. 1), the $s_{d}$ value was determined based on a position-versus-time curve for the wire tip (actually the low end of the droplet hanging to it) during its advance movement that was built by using eight frames sampled from the highspeed footage of run 3 (intermediate wire pulsation frequency). From this curve, a polynomial fit was assembled, from which the derivative function represents the speed over time. The overall $s_{d}$ value was then calculated for the last time value before the droplet detached from the wire tip, resulting in $0.61 \mathrm{~m} / \mathrm{s}$. It is hypothetically assumed that the mass of each droplet does not change during the fast advance movement of the wire $\left(m_{d}=m_{i}\right)$.

$F_{i}=\frac{m_{d} \cdot s_{d}}{\Delta t_{a}}[N]$

Figure 12 presents the mean values of the forces acting during the detachment of the droplets according to the simplified model and in dependency of the wire feed pulsation

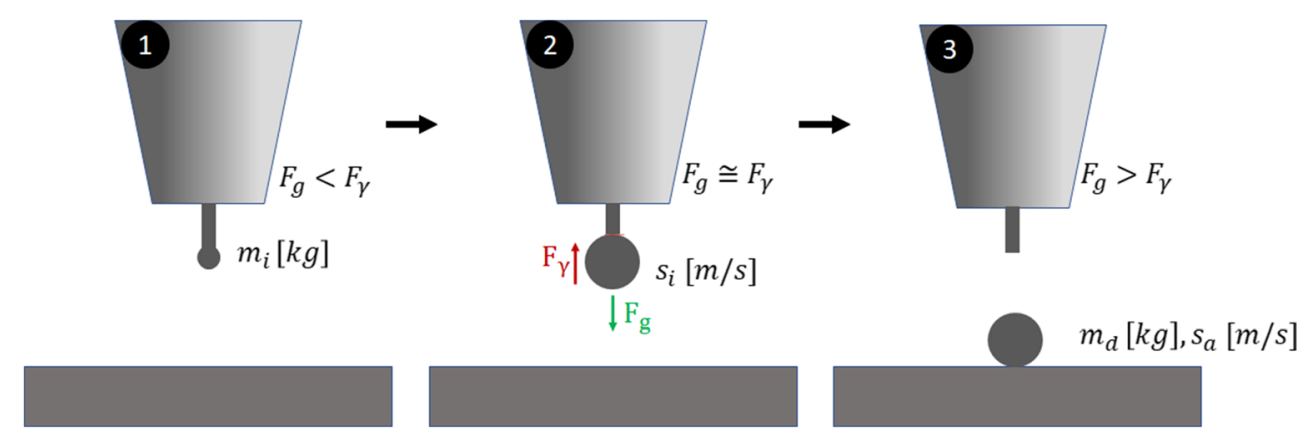




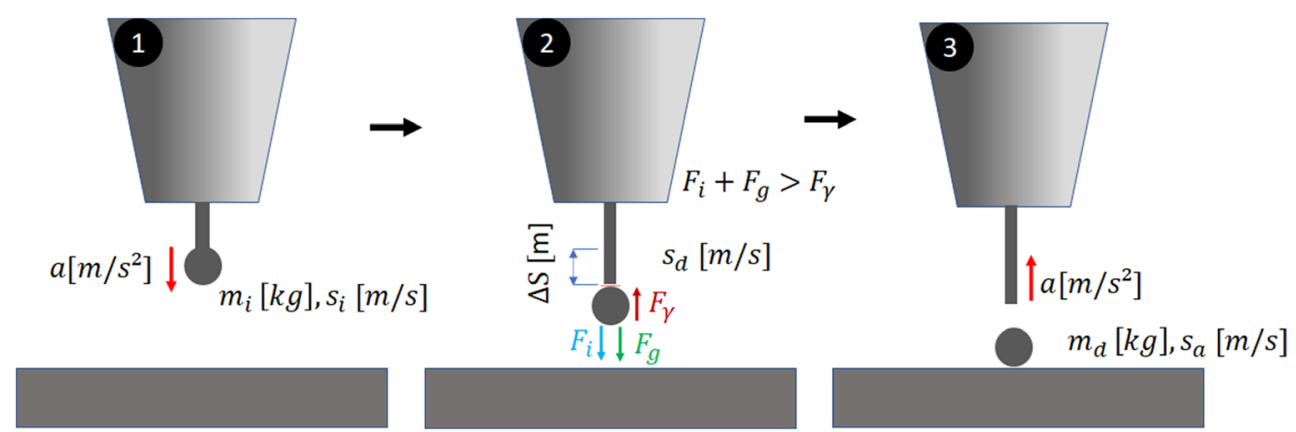

Fig. 11 Simplified physical model of a droplet detachment under globular metal transfer assisted with the wire feed pulsation, where $a$ is the wire acceleration in the advance (and also in the retreat) movement in $\mathrm{m} / \mathrm{s}^{2} ; m_{i}$ is the droplet initial mass in $\mathrm{kg} ; s_{i}$ is the droplet initial speed in $\mathrm{m} / \mathrm{s}$ (in this case, considered nil); $\Delta S$ is the distance traveled by the wire

frequency. In practice, it is known that there is quite an uncertainty when determining the surface tension coefficient value, which depends on the metal composition and temperature and the droplet real shape, and even on the environment (shielding gas composition, etc.). As seen, when the wire feed pulsation is applied, the increase in the frequency of this movement leads to the detachment of smaller droplets and, consequently, with lesser masses, which occurrence reduces the $F_{g}$ magnitude acting on them during the metal transfer. The $F_{r}$ magnitude, which is also proportional to the droplet size (diameter), experiences the same trend. However, it is worth noticing that the curves drawn over the calculated values of these forces $\left(F_{g}\right.$ and $F_{\gamma}$ ) indicate distinct behaviors; a polynomial characteristic for the gravitational force and a linear characteristic for the surface tension force. The graph in Fig. 12 suggests that, as the wire feed pulsation frequency increases, i.e., as droplets are formed with lesser masses, the $F_{g}$ value becomes smaller than the $F_{\gamma}$ value, hindering the detachment. Thus, in this case, another force is necessary to yield the droplet detachment. According to the simplified physical model proposed, this role is played by the $F_{i}$ force, which significantly adds to the result

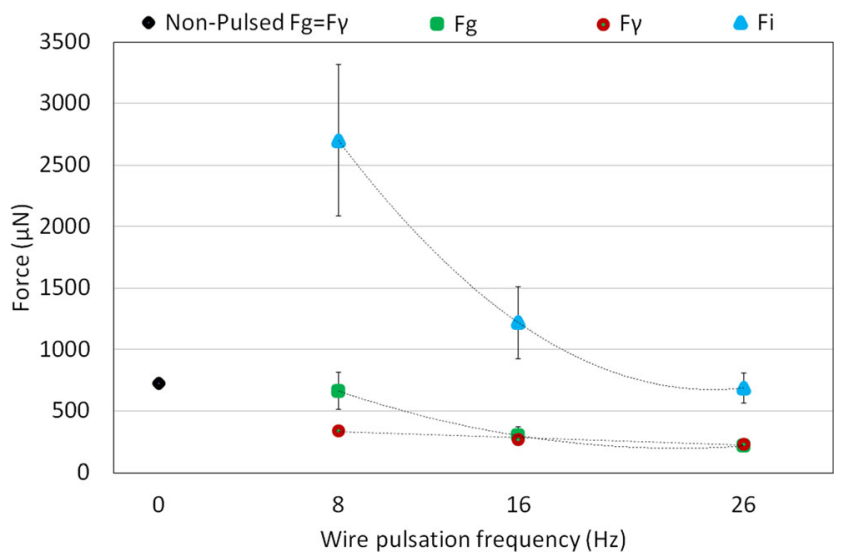

Fig. 12 Mean values of the forces acting during the detachment of the droplets as a function of the wire feed pulsation frequency for the power source in $\mathrm{CV}$ operational mode tip during its advance movement in $\mathrm{m} ; F_{i}$ is the impulse force in $\mathrm{N} ; F_{g}$ is the gravitational force in $\mathrm{N} ; F_{\gamma}$ is the surface tension force in $\mathrm{N} ; m_{d}$ is droplet mass in $\mathrm{kg}$ (equal to $m_{i}$ ); $s_{d}$ is the droplet speed at the moment of detachment in $\mathrm{m} / \mathrm{s}$; and $s_{a}$ is the droplet arrival speed in $\mathrm{m} / \mathrm{s}$

of a downward (detachment) force. The evolution of such force, as also presented in Fig. 12, descendent with the increase in the wire feed pulsation frequency, is justified by the calculus variables, being its magnitude dependent on the speed and mass of the droplets. Therefore, it is demonstrated that the $F_{i}$ force, provided by the wire feed pulsation device as applied, can favorably affect the detachment of the droplets in the GMAW process with a globular metal transfer, projecting them toward the weld pool.

For a better understanding of the previous paragraph, it is important to state that the droplet speed depends on the local gravity and the acceleration imposed by the pulsation mechanism. It should be noticed that the pulsation frequency was varied only through different dwell times (i.e., not thought stroke velocities). Therefore, the acceleration imposed to each droplet is the same, regardless the frequency changes. This was observed in the arrival speed results (Fig. 7). Since the impulse force depends on the acceleration and mass of the droplets, according to the second Newton's law, the smaller droplets associated with higher frequencies, as shown previously, entail lower forces, since the accelerations were kept virtually unchanged.

\subsection{Effect of wire feed pulsation on the weld bead penetration}

In order to provide a better understanding of the effect of the mechanical impulse over the weld penetration, it is necessary to quantify it. In these terms, the linear momentum (or quantity of motion) from the classical mechanics, a quantifiable parameter, is mentioned as one of the governing factors in the weld bead formation. The quantity of motion transferred to the weld pool by the mechanical collision of the droplets at high speeds impacting on it has the potential to cause its depression, and, by that, to make the thermal action of the arc more effective, facilitating fusion penetration. However, by itself, the linear momentum does not express the effects of the droplets 
in action on a time basis. A metal transfer with large droplets, for instance, may produce a large momentum, but it does not necessarily act significantly in the weld bead penetration. Thus, Scotti and Rodrigues [23, 24] proposed expressing and quantifying the momentum, concerning its role in the weld bead formation, in a different way. According to these authors, it would be reasonable to think of a better way to take into account the effect of such a mechanical characteristic of the metal transfer. They accomplished it by considering the number of times that such momentum is transferred to the weld pool in a time interval. Hence, they introduced the concept of effective momentum $\left(M_{e}\right)$, calculated according to Eq. 6. This factor is devised from the mechanical principle of the linear quantity of motion (given by the product of the mass of the droplet by its speed when arriving at the weld pool) in association with the droplet detachment frequency $\left(f_{d}\right)$, which results in a discrete force. After dividing such intermittent force by the welding travel speed (WTS), its action during the time to form the weld bead is finally incorporated and completes the $M_{e}$ concept.

$M_{e}=\frac{m_{d} \cdot s_{a} \cdot f_{d}}{W T S}[\mathrm{~kg} / \mathrm{s}]$

Another way of expressing and quantifying the mechanical effect delivered by the impact of the droplets on the weld pool, proposed in this current work, would be by means of the kinetic energy input $\left(E_{k i}\right)$. This nomenclature is proposed in order to establish an analogy with the heat input $\left(H_{i}\right)$, which can be briefly understood as the welding arc energy (the product of the arc voltage and the welding current divided by the travel speed of the torch/arc) that is actually supplied to the workpiece, i.e., after the efficiency of the process is considered, per unit of weld bead length. The $E_{k i}$ factor can be therefore calculated according to Eq. 7, where $m_{d}$ is the droplet mass; $s_{a}$ is the arrival speed of the droplet; $f_{d}$ is the detachment frequency; and WTS is the welding travel speed. As seen, in contrast to the $M_{e}$ case, the $E_{k i}$ factor takes the square of the droplet speed. Hereby, the droplet speed effect might be revealed with more significance.

$E_{k i}=\frac{m_{d} \cdot s_{a}^{2} \cdot f_{d}}{2 \cdot W T S}[\mathrm{~J} / \mathrm{m}]$

In fact, to reach a rather proper parallel of energy terms and meanings, the $H_{i}$ could be called as thermal energy input $\left(E_{t i}\right)$. Anyway, by distinguishing the forms that the welding process has to affect the weld bead formation via a thermal and a mechanical contribution of the same nature, in terms of being quantitative properties measured by the same units (both in terms of energy input per unit of weld bead length), might allow a more straightforward comparison concerning the role played by each part on the weld bead formation scenario.

As it was previously demonstrated that the mechanical impulse provided by the wire feed pulsation device is capable of influencing the droplet detachment in the globular metal transfer, as well as the weld bead formation, both forms of measuring the magnitude of the mechanical contribution $\left(M_{e}\right.$ and $\left.E_{k i}\right)$ to the resultant weld bead penetration are presented in Table 2 .

Figure 13 shows the variation in the $M_{e}$ factor in relation to the wire feed pulsation frequency for both power source operational modes. In contrast to the $\mathrm{CC}$ mode, with the $\mathrm{CV}$ mode and when the wire feed pulsation was applied, an increase in the $M_{e}$ values can be observed, independently from the pulsation frequency used. From the kinetic energy perspective, Fig. 14 suggests that the $E_{k i}$ factor exhibits the same information, although there is an increase in the proportional changes in the $E_{k i}$ levels in relation to those observed in the $M_{e}$ case. In comparison with the conventional wire feeding case $(0 \mathrm{~Hz})$, when the wire feed pulsation was applied, the $M_{e}$ factor generally increased around $16 \%$ with the power source in the CV mode and decreased around $17 \%$ with it operating in the CC mode. Regarding the $E_{k i}$ factor, and also in contrast to the conventional wire feeding case $(0 \mathrm{~Hz})$, its magnitude

Table 2 Effective momentum $\left(M_{e}\right)$ and kinetic energy input $\left(E_{k i}\right)$ values for each welding condition evaluated

\begin{tabular}{|c|c|c|c|c|c|c|c|c|}
\hline Run & $\begin{array}{l}\text { Wire pulsation } \\
\text { frequency }(\mathrm{Hz})\end{array}$ & $\begin{array}{l}\text { Power source } \\
\text { mode }\end{array}$ & $\begin{array}{l}\text { Droplet detachment } \\
\text { frequency } \\
(\mathrm{Hz})\end{array}$ & $\begin{array}{l}\text { Mean droplet } \\
\text { mass }\end{array}$ & $\begin{array}{l}\text { Mean droplet arrival } \\
\text { speed }(\mathrm{m} / \mathrm{s})\end{array}$ & $\begin{array}{l}\text { Mean Weld } \\
\text { penetration }(\mathrm{mm})\end{array}$ & $\begin{array}{l}M_{e} \\
\times 10^{-1} \\
(\mathrm{~kg} / \mathrm{s})\end{array}$ & $\begin{array}{l}E_{k i} \\
\times 10^{-2} \\
(\mathrm{~J} / \mathrm{m})\end{array}$ \\
\hline 1 & 0 & $\mathrm{CV}$ & 8.4 & 74.180 & 0.474 & 0.963 & 0.988 & 2.619 \\
\hline 2 & 8 & & 7.9 & 67.511 & 0.593 & 1.239 & 1.186 & 4.390 \\
\hline 3 & 16 & & 15.6 & 30.512 & 0.591 & 1.746 & 1.077 & 4.040 \\
\hline 4 & 26 & & 22.4 & 23.385 & 0.607 & $(*)$ & 1.177 & 4.476 \\
\hline 5 & 8 & $\mathrm{CC}$ & 9.7 & 56.004 & 0.391 & 1.045 & 0.636 & 1.877 \\
\hline 6 & 16 & & 15.7 & 26.725 & 0.553 & 1.508 & 0.700 & 2.913 \\
\hline
\end{tabular}

(*) At $26 \mathrm{~Hz}$, despite the arc stability, the equipment was not capable of depositing a weld bead long enough to allow consistent penetration measurements (this frequency is close to the frequency limit of the pulsation device, which prevented long welding time) 


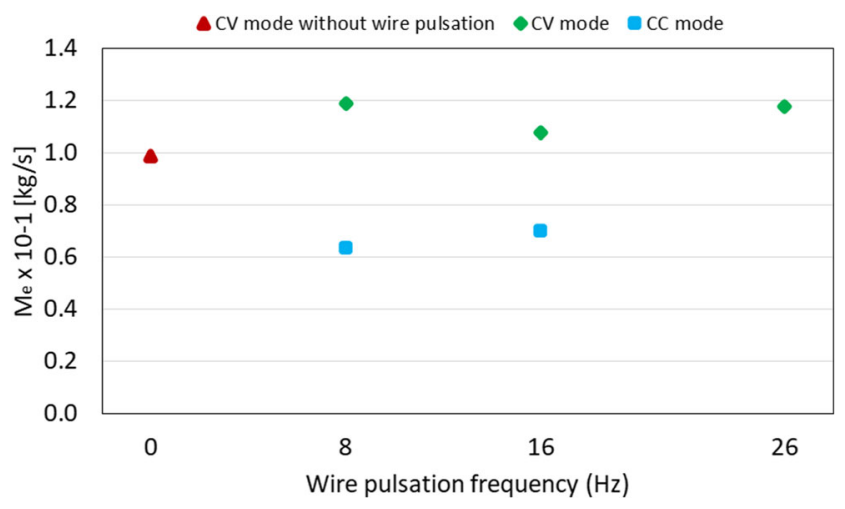

Fig. 13 Effective momentum $\left(M_{e}\right)$ for each wire feed pulsation frequency and power source operational mode combination

generally increased around $90 \%$ when the wire feed pulsation was applied with the power source in the $\mathrm{CV}$ mode, whereas it did not reveal significant changes with the $\mathrm{CC}$ mode. These facts all indicate that the $E_{k i}$ factor can tell the same effects of the $M_{e}$ factor, as it was expected since the linear momentum and the kinetic energy of objects in motion, in this case, the droplets, are interconnected from the classical mechanics. But the $E_{k i}$ factor indeed shows the effects in a more intense way. Considering it is expressed in the same units of the heat input term $\left(H_{i}\right)$, which is classically employed in arc welding, the $E_{k i}$ factor might be used to replace the $M_{e}$ term allowing a direct comparison and fractioning when considering the energy, both thermal and mechanical, imposed by the process.

From both the $M_{e}$ and $E_{k i}$ level perspectives, with the wire feed pulsation, it would be expected that the weld penetration could increase with the power source in the CC mode and decrease, or at least be kept similar, with it in the CV mode for the two correspondent pulsation frequencies mainly assessed ( 8 and $16 \mathrm{~Hz}$ ). It is noticeable in Fig. 12, for the same pulsation frequencies, that the penetration was deeper with the $\mathrm{CV}$ mode than with the $\mathrm{CC}$ case, which is in agreement with the higher values of the $M_{e}$ and $E_{k i}$ factors also with the CV mode. However, when they are individually considered, the trend in the change of these factors is opposite according to the power source mode used; for frequencies from 8 to $16 \mathrm{~Hz}$, the

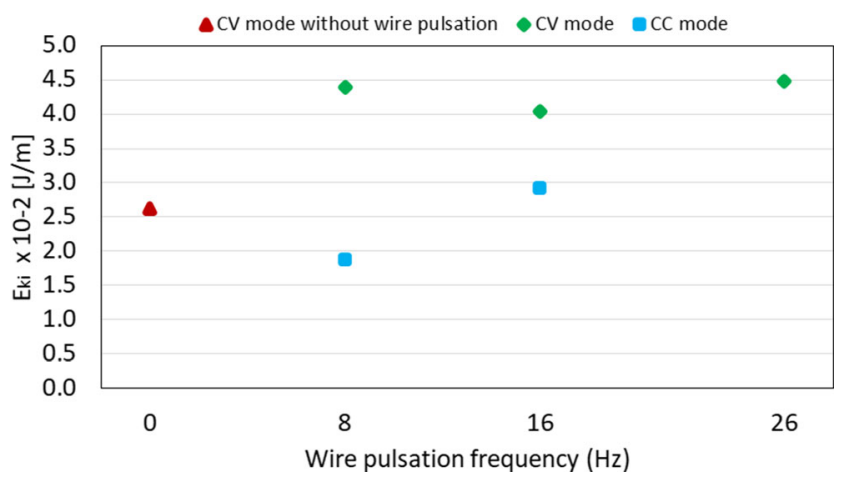

Fig. 14 Kinetic energy input $\left(E_{k i}\right)$ for each wire feed pulsation frequency and power source operational mode combination
$M_{e}$ and $E_{k i}$ levels tend to decrease with the CV mode and rise with the $\mathrm{CC}$ mode. If the numbers with the wire feed pulsation are compared with those without it, the results are even more controversial, indicating that, at least for the levels imposed by the wire feed pulsation and given the other welding conditions employed, other factors than the $M_{e}$ and $E_{k i}$ factors might be playing a leading role to define the weld bead penetration. A hypothesis to be addressed in future investigations would be to compare both the mechanical factors $\left(M_{e}\right.$ and $\left.E_{k i}\right)$ concerning the effect in the weld penetration with the spray transfer mode, which certainly produces much faster droplets than does the globular mode (even if aided by the mechanical impulse as here applied). But meanwhile, in the present work, the increase in penetration cannot be fully explained based on the $M_{e}$ and $E_{k i}$ factors, although there is evidence of their positive contribution (increasing the penetration) when the wire feed pulsation was combined with the power source in the CV mode. These findings are in accordance with Choo et al.'s [16], who states that the momentum of the falling droplet was not sufficient to cause it to penetrate into the pool. Thus, other factors and their effects, concurrent with and/or even still related to the mechanical impact of the droplets on the weld pool and its repercussion, must be watched closely.

As listed in Table 1, a slight reduction in the welding mean current was noticed for the tests carried out with the wire feed pulsation combined with the power source in the CV mode, while no significant difference took place in the combination with the CC mode. From the mean current point of view, its inferior level causes less heat input to the plate (thermal effect). This way, a small reduction in the weld penetration would be expected when the wire feed pulsation was applied with the power source in the CV mode. From the same logic, the weld penetration should not change when the wire feed pulsation was applied with the $\mathrm{CC}$ mode. By looking at the arc voltage mean values in Table 1, it is noticeable that the levels did not significantly change for the power source in the $\mathrm{CV}$ mode with the introduction of the wire feed pulsation, but they increased for the cases in which this feeding technique was in combination with the CC mode. From the premise that the arc voltage directly reflects its length, when working with longer arc lengths, a decrease in penetration would be expected as the arc is less concentrated (low energy density) over the welding area. Since the weld penetration observed was deeper when the wire feed pulsation was applied with the CC mode, there is also no evidence that the arc length was predominant to justify the results. By looking at the true arc energy, also in Table 1, the behavior follows a similar trend to what was observed regarding the welding current, and the overall variations were minor. Therefore, as observed for the $M_{e}$ and $E_{k i}$ factors concerning the mechanical effects due to the impact of the droplets, the contribution in terms of thermal effects due to the welding current and arc voltage likewise does not justify the increase in penetration as the wire feed pulsation frequency is raised. As 
typically found in arc welding, especially in the GMAW process and its derivative versions, a multi-phenomenon interaction regulates the weld bead formation, as illustrated in Fig. 1, which makes it difficult to understand, even more when a new player, and its interactions with the other acting mechanisms, is brought to the scenario, as is the case of the wire feed pulsation.

Hence, there must be other factors prevailing and then governing the weld bead formation in terms of penetration. Among the possibilities, the Marangoni flow phenomenon stands out. A variation in the surface tension acting on the weld pool, which induces the Marangoni flow, is generated by surface tension gradients and the consequent interfacial pressure. Thus, the change in the penetration depth of a weld bead would result from the variations in the liquid metal movement pattern taking place in its weld pool, which affects the resultant heat convection [12].

It has been shown (Fig. 6) that an increase in the wire feed pulsation frequency boosts the number of droplets being detached, whereas it reduces their masses. From that, hypothetically one can consider that smaller droplets facilitate their dive into the molten pool toward the weld root direction, enhancing their hydrodynamic behavior. As an indication of support to this hypothesis, it was also observed, from the high-speed footages, that there is a mechanical impulse guidance action promoted by the wire feed pulsation device which helps to drive the droplets into the central region of the weld pool (Fig. 15(a)). A large number of droplets impinging onto a nearly same point could help the mass and heat transfer to occur from the top to the root of the weld pool, increasing the weld penetration depth in a consistent (concentrated) fashion. This occurrence is not verified with the conventional globular transfer (Fig. 15(b)), i.e., without the wire feed pulsation. Moreover, the hydrodynamics involved cannot be neglected. The hydrodynamic drag, i.e., the force acting opposite to the relative motion of the droplet moving across to the surrounding weld pool fluid before they completely merge in terms of mass and heat, might be also determinant. From the fluid dynamics, the drag force is directly proportional to the relative velocity and the cross-sectional area of the moving body, in this case, the droplet. Thus, the drag induced by the faster droplets transferred with the wire feed pulsation might partially hold back the penetrationincreasing effect expected from the mechanical impulse. But in terms of the cross-sectional area of the droplets being transferred, in a complementary way to the guidance action, Fig. 16 schematically illustrates that the size of the droplets may hinder their dive into the weld pool, contributing to define the weld penetration. Smaller droplets, for inducing less drag, tend to reach deeper regions into the weld pool.

Related to the Marangoni flow, further possible explanations for the change in penetration observed can be drawn according to the findings of other authors. Choo et al. [16]
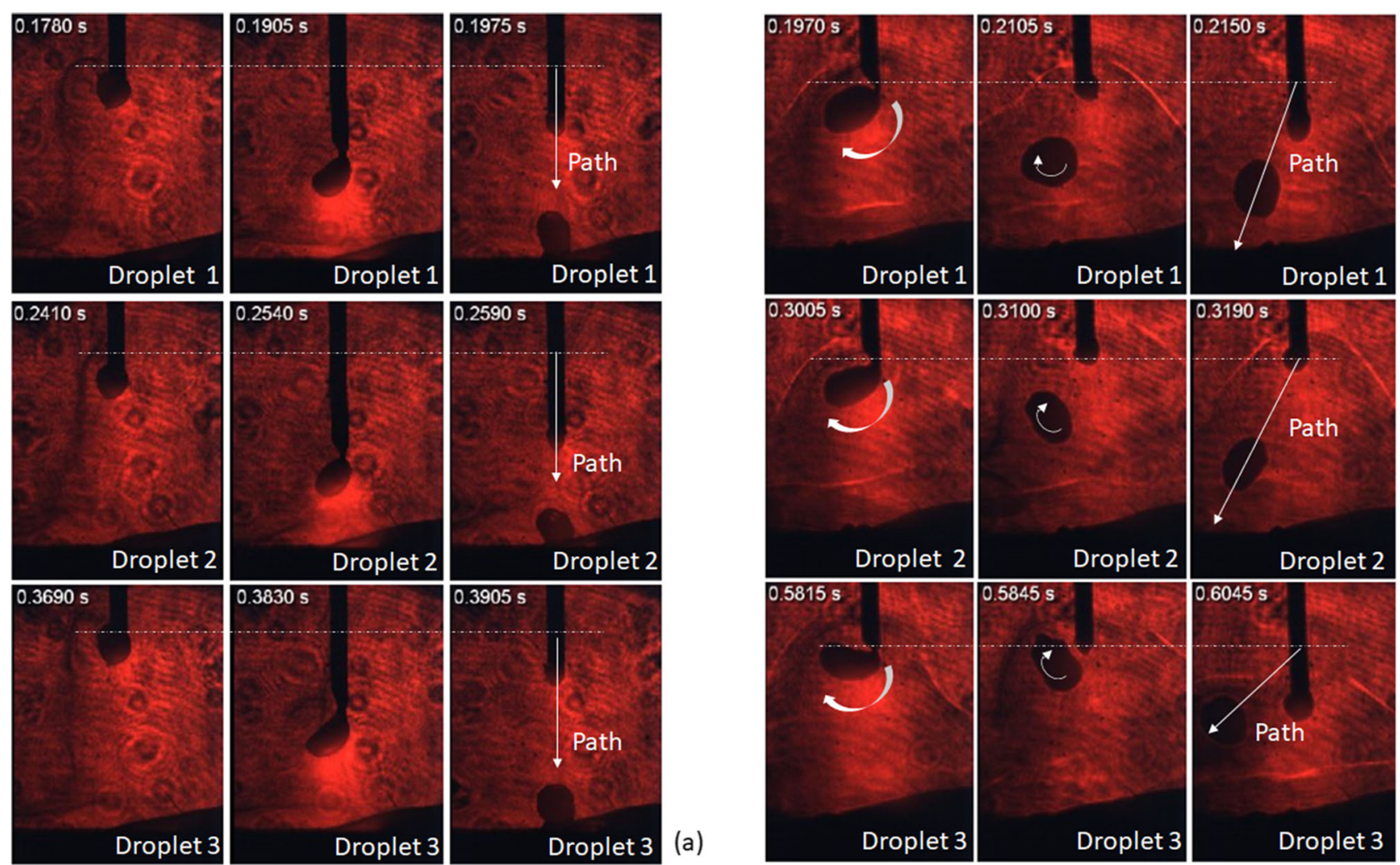

(b)

Fig. 15 Detachment dynamics with a sequence of three images for each random droplet assessed (from left to right and top to bottom): (a) with wire feed pulsation $(16 \mathrm{~Hz}-\mathrm{CV})$; (b) without wire feed pulsation $(0 \mathrm{~Hz}-\mathrm{CV})$ 
point out that the flow induced by the difference in surface tension between the droplet and the liquid pool is the dominant factor in defining the direction and intensity of the fluid flow within the weld pool. According to them, the impingement of the droplets in the weld pool affects the surface tension gradient as a step function. According to Davies et al. [17], one could expect that droplets hotter than the weld pool would have lower surface tension. From this, as the droplets with the wire feed pulsation are detached and transferred faster due to the mechanical impulse, they are allowed to be less overheated and for shorter periods (less time being exposed to the arc), ending up with them having higher surface tension levels, interfering in the resulting surface tension gradient in the weld pool and thus affecting the convective flow. Besides, the lower droplet temperature also entails higher density, which affects the buoyancy force acting in the droplet when already in the weld pool. The bigger difference between the droplet and pool densities would favor a downward fluid motion. Finally, according to Jaidi e Dutta [18], the effect of the falling/throwing droplets in the GMAW process and the resultant intensified thermal diffusivity within the weld pool, caused by the increased turbulence that is generated, tend to make the molten pool and, hence, the weld bead deeper. With the wire feed pulsation, the increase in the number of droplets colliding with the weld pool and with faster speeds could intensify its turbulence and hence boost the weld penetration. As the arc, in this case, is also being constantly changed in length by the wire tip cyclical movement, the plasma jet would follow and also contribute to the stirring of the weld pool.

The coupling of the wire feed pulsation with the globular metal transfer, despite not clearly showing effects through factors like $M_{e}$ e $E_{k i}$ to express the influence of the correspondent mechanical energy imposed into the weld pool, seems to exhibit the capacity for change the way the droplets interact with the weld pool, such as the way they enter into it, which results in an ability to increase the weld penetration depth without necessarily increasing the process thermal energy. In this case, the Marangoni flow, and its related factors, seems to chiefly account for the changes verified in the weld penetration in the GMAW process as applied with the wire feed pulsation technique. The fact of imposing rapid advance and retreat cyclical movements to the wire along the feeding direction to the weld pool, as just mentioned, might affect the hydrodynamics and temperature of the droplets, as well as the weld pool flow characteristics (turbulence) and surface tension. Although the exact contribution of each one of these factors is rather complex, all the hypotheses considered imply that they would change the weld pool convective mass and heat transfer behavior as a consequence of its surface tension variations, i.e., the Marangoni flow would be diversely affected by the wire feed pulsation.

Hence, the way that the dynamics of the wire feeding is performed, without or with pulsation, for instance, should be also considered for the hierarchical representation of the weld bead formation phenomena in the GMAW process delineated in Fig. 1. As an attempt to complete this picture, in terms of the mechanisms that determine whether the effects are thermal, mechanical, or either a combination of both (thermomechanical), Fig. 17 incorporates the Marangoni flow in Fig. 1 (although debatable if the Marangoni mechanism would yield either a thermal or a mechanical effect on the weld bead formation, the authors of this work preferred to classify it linked with the mechanical effect). Also, the base and filler materials and the way that the later one is actually fed into the fusion zone (arc/pool), summarized here as feeding dynamics, are included as complemental parameters that influence this and other mechanisms in the scenario of the weld bead formation phenomena. Likewise, the feeding dynamics parameters, also affect to some degree other mechanisms involved, which hence reinforce their influences on the thermal and/or mechanical effects. If the wire feed pulsation is applied with the power source in the $\mathrm{CV}$ mode, the magnetic field around the electrode-wire and electric arc would increase and decrease as the welding current if free to rise and fall as the arc length shortens and lengthens, respectively. As the arc length is varied according to the wire feed pulsation, the arc-metal coupling mechanism is also affected when the power source is in the $\mathrm{CC}$ or $\mathrm{CV}$ mode; the coupling area is directly proportional
Fig. 16 Schematic illustration of the influence of the droplet mass and size over the weld bead penetration: (a) a smaller droplet easily entering and then contributing to the deep penetration; (b) a bigger droplet uneasily entering and then contributing to shallow penetration

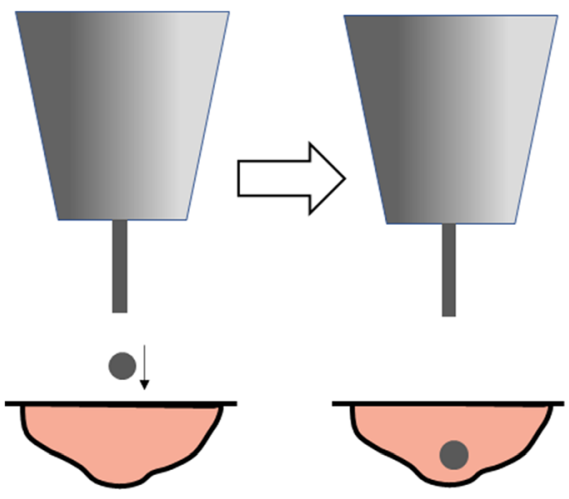

(a)

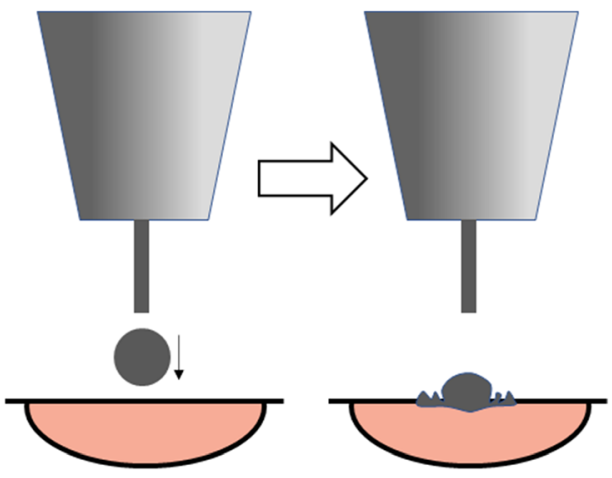

(b) 


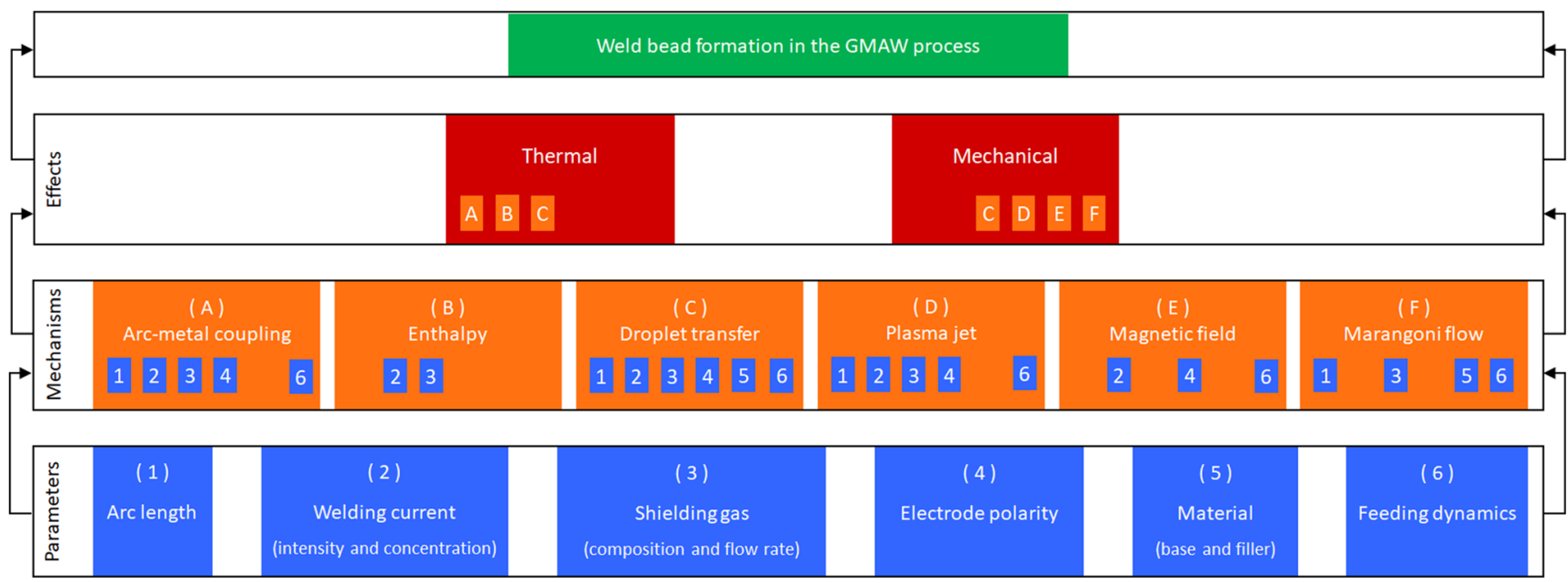

Fig. 17 Up-to-date hierarchical representation of the weld bead formation phenomena in the GMAW process (based on Scotti and Ponomarev [9] and completed after the findings of the present work)

to the arc length. Since the welding current and arc length vary as the electrode-wire advances and retreats cyclically, the plasma jet mechanism is also affected.

Specifically regarding the filler material parameter, inferences over the effect of the wire diameter and chemical composition may be rather complicated. The wire diameter could affect the welding parameters such as current and arc length, which affect the droplet formation. As the results found in this work show, there is a relationship between the droplet growth behavior and the detachment forces. The wire chemical composition, with possible significant surface tension variation, may turn the molten metal more or less fluid. The wire thermal conductivity may as well affect the droplet growth process, as well as its surface tension, if more or less heat concentrates in the wire tip. The melting rate would also be different, meaning that a different welding current would be entailed. Changes in other physical properties, such as filler and base material densities, might be also relevant to the droplet and weld bead formation. Thus, new operational conditions would be established and the appropriated wire feed pulsation frequencies would have to be experimentally assessed. Thus, increasing or decreasing the wire diameter or changing its chemical composition and producing the correlated changes in welding parameters could affect the predominant mechanisms acting over bead formation, and different results might be found regarding fusion penetration. Still, the overall effect of the wire feed pulsation in helping the detachment and directing of the droplets is expected to be similar to what was observed in this work.

Despite all the additions in Fig. 1, the complexity involving the governing factors in the weld bead formation remains, especially in the GMAW process, and the picture just completed in Fig. 17 is most likely to undergo continual updates as new findings and understandings connected to the phenomena are unveiled.

\section{Conclusions}

This work aimed at contributing to the understanding of how the wire feed pulsation approach applied to the GMAW process interferes in the transfer of the metal droplets, as well as on how the wire feed pulsation interaction with the molten pool enhances the bead penetration depth. Based on the welding conditions employed, the main conclusions drawn are the following:

- The increase in the wire feed pulsation frequency, for a same wire feed speed, intensifies the detachment frequency of the droplets, while their volume and mass are reduced, having the globular metal transfer frequency and volume as a benchmark (the wire feed pulsation adds an impulse component to the forces that act on the detachment of the droplets and increases their flight speed).

- The simplified physical model proposed in this work showed that the impulse force magnitude dependents on the speed and mass of the droplets.

- Therefore, if a non-adequate combination of wire movement and droplet size at its tip is reached, process instabilities (metal transfer inconsistencies) related to the instant of detachment arises (the quantification of this relationship is foreseen for future work).

- The wire feed pulsation frequency set at $16 \mathrm{~Hz}$ matched the detachment of one droplet per pulse, resulting in a stable metal transfer with the droplets being straightly projected toward the weld pool, which contributed to a centralized and increased penetration profile.

- The effective momentum and, as here introduced, the kinetic energy input, used to quantify the mechanical effect of the droplets impinging the weld pool, contribute to increasing the fusion penetration.

- However, the general penetration enhancement observed when the wire feed pulsation was applied could not be 
fully explained either by the process electric signals (welding current, arc voltage, and true arc energy) and their thermal effects or by factors related to its mechanical effects (effective momentum and kinetic energy input).

- Therefore, the simplified physical model included another acting force toward droplet detachment, related to weld pool convective mass and heat transfer behavior (Marangoni flow), as a consequence of its surface tension variations, which is influenced, among other parameters, by the material composition, hydrodynamics, and temperature of the droplets, as well as by the own weld pool material composition and flow characteristics (turbulence).

Summing up, the complexity involving the governing factors in the weld bead formation remains, especially in the GMAW process, but it will certainly experience continual illumination as new findings and understandings connected to the phenomena are unveiled, as it was herein accomplished regarding the way that the wire feeding dynamics is performed (frequency, amplitude, type of movement applied, etc.).

Acknowledgments The authors acknowledge the Center for Research and Development of Welding Processes (Laprosolda) at the Federal University of Uberlândia for the laboratorial infrastructure and technical support.

Funding Open access funding provided by University West. This study was supported by the Brazilian Coordination for the Improvement of Higher Education Personnel (CAPES), through Finance Code 001, and by the Brazilian National Council for Scientific and Technological Development (CNPq), through grants 302863/2016-8 and 315092/2018-1.

Open Access This article is licensed under a Creative Commons Attribution 4.0 International License, which permits use, sharing, adaptation, distribution and reproduction in any medium or format, as long as you give appropriate credit to the original author(s) and the source, provide a link to the Creative Commons licence, and indicate if changes were made. The images or other third party material in this article are included in the article's Creative Commons licence, unless indicated otherwise in a credit line to the material. If material is not included in the article's Creative Commons licence and your intended use is not permitted by statutory regulation or exceeds the permitted use, you will need to obtain permission directly from the copyright holder. To view a copy of this licence, visit http://creativecommons.org/licenses/by/4.0/.

\section{References}

1. DeRuntz BD (2003) Assessing the benefits of surface tension transfer welding to industry. J Ind Technol 19(4):1-8. http://citeseerx.ist. psu.edu/viewdoc/download?doi=10.1.1.577.723\&rep= rep1\&type $=$ pdf

2. Das S, Vora JJ, Patel V (2019) Regulated metal deposition $\left(\mathrm{RMD}^{\mathrm{TM}}\right)$ technique for welding applications: an advanced gas metal arc welding process. In book: Advances in Welding Technologies for Process Development https://doi.org/10.1201/ 9781351234825-2
3. Jorge VL, Scotti FM, Reis RP, Scotti A (2020) The effect of pulsed cold-wire feeding on the performance of spray GMAW. Int J Adv Manuf Technol 107:3485-3349. https://doi.org/10.1007/s00170020-05247-4

4. Kah P, Suoranta R, Martikainen J (2013) Advanced gas metal arc welding processes. Int J Adv Manuf Technol 67:655-674. https:// doi.org/10.1007/s00170-012-4513-5

5. Wu Y, Kovacevic R (2002) Mechanically assisted droplet transfer process in gas metal arc welding. P I Mech Eng B-J Eng 216(4): 555-564. https://doi.org/10.1243/0954405021520247

6. Lebedev V, Reisgen U, Lendiel I (2016) Study of technological opportunities of GMA welding and surfacing with pulse electrode wire feed. Weld World 60(3):525-533. https://doi.org/10.1007/ s40194-016-0321-0

7. Guo N, Du Y, Maksimov S, Feng J, Yin Z, Krazhanovskyi D, Fu Y (2018) Study of metal transfer control in underwater wet FCAW using pulsed wire feed method. Weld World 62:87-94. https://doi. org/10.1007/s40194-017-0497-y

8. Guo N, Huang L, Du Y, Cheng Q, Fu Y, Feng J (2019) Control of droplet transition in underwater welding using pulsating wire feeding. Materials 12(10):1715. https://doi.org/10.3390/ma12101715

9. Scotti A, Ponomarev V (2008) MIG/MAG welding - better understanding, better performance, Ed. Artliber, 2a . Edition, 2008, 284. (in Portuguese)

10. Dass A, Moridi A (2019) State of the art in directed energy deposition: from additive manufacturing to materials design. Coatings 9: 418. https://doi.org/10.3390/coatings9070418

11. Heiple CR, Roper JR, Stagner RT, Aden RJ (1983) Surface active element effects on the shape of GTA, laser and electron beam welds. Weld J 62:72-77. http://files.aws.org/wj/supplement/WJ 1983 03 s72.pdf

12. Mills K, Keene B, Brooks R, Shirali A (1998) Marangoni effects in welding. Phil Trans R Soc Lond A 356:911-925. https://doi.org/10. 1098/rsta.1998.0196

13. Fujii H, Sato T, Lu S, Nogi K (2008) Development of an advanced A-TIG (AA-TIG) welding method by control of Marangoni convection. Mater Sci Eng 495:296-303. https://doi.org/10.1016/j. msea.2007.10.116

14. Xu L, Dong B, Wei H, Yang L (2007) Marangoni convection and weld shape variation in A-TIG welding process. Theor Appl Fract Mech 48:178-186. https://doi.org/10.1016/j.tafmec.2007.05.004

15. Modenesi PJ (2015) The chemistry of TIG weld bead formation. Weld Int 29(10):771-782. https://doi.org/10.1080/09507116.2014. 932990

16. Choo RTC, Mukai K, Toguri JM (1992) Marangoni interaction of a liquid droplet falling onto a liquid pool. Weld $\mathrm{J} 4: 139 \mathrm{~s}-146 \mathrm{~s}$. https://app.aws.org/wj/supplement/WJ_1992_04_s139.pdf

17. Davies MH, Wahab MA, Painter MJ (2000) An investigation of the interaction of a molten droplet with a liquid weld pool surface: a computational and experimental approach. Weld J 79:18s-23s https://app.aws.org/wj/supplement/01-2000-DAVIES-s.pdf

18. Jaidi J, Dutta P (2004) Three-dimensional turbulent weld pool convection in gas metal arc welding process. Sci Technol Weld Join 9(5):407-414. https://doi.org/10.1179/136217104225021814

19. Jaidi J, Dutta $P$ (2001) Modeling of transport phenomena in a gas metal arc welding process. Numer Heat Tr A-Appl 40(5):543-562. https://doi.org/10.1080/10407780152619838

20. Reis RP, Scotti A, Jorge VL, Larquer TR (2019) Device for pulsed wire feeding in metal fusion-based deposition processes. Patent no. BR 1020190124865 (in Portuguese)

21. Jorge VL, Santos CH, Scotti FM, Larquer TR, Mota CP, Reis RP, Scotti A (2018) Development and evaluation of wire feeding pulsing techniques for arc welding. Soldag Insp 23(3):326-339. (in Portuguese). https://doi.org/10.1590/0104-9224/si2303.03

22. Rywotycki M, Malinowski Z, Giełżecki J, Gołdasz A (2014) Modelling liquid steel motion caused by electromagnetic stirring 
in continuous casting steel process. Arch Metall Mater 59:487-492. https://doi.org/10.2478/amm-2014-0080

23. Scotti A, Rodrigues L (2009) Determination of momentum as a mean of quantifying the mechanical energy delivered by droplets during MIG/MAG welding. Eur Phys J Appl Phys 45:11201. https://doi.org/10.1051/epjap:2008196

24. Scotti A, Rodrigues L (2009) Determination of the momentum of droplets impinging on the pool during aluminium GMAW. Soldag
Insp 14(4):336-343. https://doi.org/10.1590/S010492242009000400008

Publisher's note Springer Nature remains neutral with regard to jurisdictional claims in published maps and institutional affiliations. 